\title{
Experimental analysis of perforation of glass/polyester structures subjected to high-velocity impact
}

\author{
Brenda L. Buitrago ${ }^{\mathrm{a}, \mathrm{b}}$, Shirley K. García-Castillo ${ }^{\mathrm{a}}$, Enrique Barbero ${ }^{\mathrm{a}, *}$ \\ a Department of Continuum Mechanics and Structural Analysis University Carlos III of Madrid Avda. de la Universidad 30, 28911 Leganés, Madrid, Spain \\ ${ }^{\mathrm{b}}$ Department of Industrial Technology University Simón Bolivar Valle de Sartenejas, Caracas, Venezuela
}

\begin{abstract}
A B S T R A C T
In this paper the ballistic behaviour of several glass/polyester laminate structures was studied, evaluating the residual velocity of the projectile and the damage area. Three monolithic laminates of different thicknesses and two multiplate laminate structures were analyzed: one of a sandwich type with face sheets of glass/ polyester and a foam core, and another made with the same face sheet, which were separated by a distance equal to the thickness of the core. It was found that laminates of greater thickness show a larger damage area and a greater ballistic limit. The influence of the core on the ballistic limit of multiplate laminate structures is negligible but, nevertheless, the extension of the damage area in the back face sheet is increased.
\end{abstract}

Keywords:

Composite materials

Sandwich

Multiplate structure

Impact behaviour

Aerospace materials also maintaining the other parameters (geometry, material, etc.) under the same conditions.

This study analyzes the behaviour of three monolithic laminates of different thicknesses and two multiplate laminates when subjected to high velocity impact under the same testing conditions. In every case, the same E glass/polyester fabric was used.

\section{Experimental procedure}

Five structures made of E glass/polyester woven laminate were studied: three monolithic laminates with thicknesses of 3, 6, and $12 \mathrm{~mm}$ and two multiplate laminate structures; one of the sandwich type with face sheets of $3 \mathrm{~mm}$ thick and a $30 \mathrm{~mm}$ PVC foam core, and another designed as spaced plates, consisting of two $3 \mathrm{~mm}$ laminates separated $30 \mathrm{~mm}$ apart. The experimental tests used an A1G + gas gun, manufactured by Sabre Ballistics. The specimens were impacted by spherical steel projectiles of $1.7 \mathrm{~g}$ and $7.5 \mathrm{~mm}$ in diameter. For a wide range of impact velocities from $80 \mathrm{~m} / \mathrm{s}$ to $780 \mathrm{~m} / \mathrm{s}$, two different types of gas were used: helium to achieve the highest velocities, and Stargon ${ }^{\circledR}$ (a mixture of argon, carbon dioxide, and oxygen) for the lowest velocities. The tests were recorded by a high velocity video camera (APX PHOTRON FASTCAM) with a data acquisition system capable of taking up to 120,000 frames per second. For better recording quality, a high intensity light source, model ARRISUN 12 plus, was used. Data gathered from the images were used to estimate the projectile velocity.

For all of the structures which were impacted, and given that the composite laminates were translucent, the extension of the damage area was determined with optical techniques [5].
* Corresponding author. Tel.: +34 9162499 65; fax: +34 916249430.
E-mail address: ebarbero@ing.uc3m.es (E. Barbero). URL: http://www.uc3m.es/mma (E. Barbero). 


\section{Results}

Fig. 1 shows the relationship between the impact velocity and residual velocity on all of the structures tested. The fitting curves shown in the figure were calculated using the Lambert Jonas model [6] which relates residual velocity to impact velocity by means of the following equation:

$v_{\mathrm{R}}=A \cdot\left(v_{0}^{p}-\mathrm{V}_{B L}^{p}\right)^{1 / p}$

where $v_{\mathrm{o}}$ is the impact velocity of the projectile, $v_{\mathrm{BL}}$ the ballistic limit, $v_{\mathrm{R}}$ the residual velocity of the projectile and $A$ and $p$ are empirical parameters. In this study, it was not possible to calculate the ballistic limit in a determinist way because there is an impact velocity interval in which the structure may or may not be entirely perforated; in addition, the residual velocity of the projectile from the gas gun cannot be totally controlled. Therefore, in this study, the ballistic limit was estimated using Eq. 1 (Table 1 ) by a least square fitting method.

The influence of the foam core was negligible, with an observed difference of $3.5 \%$ in the ballistic limit between the multiplate

(a)

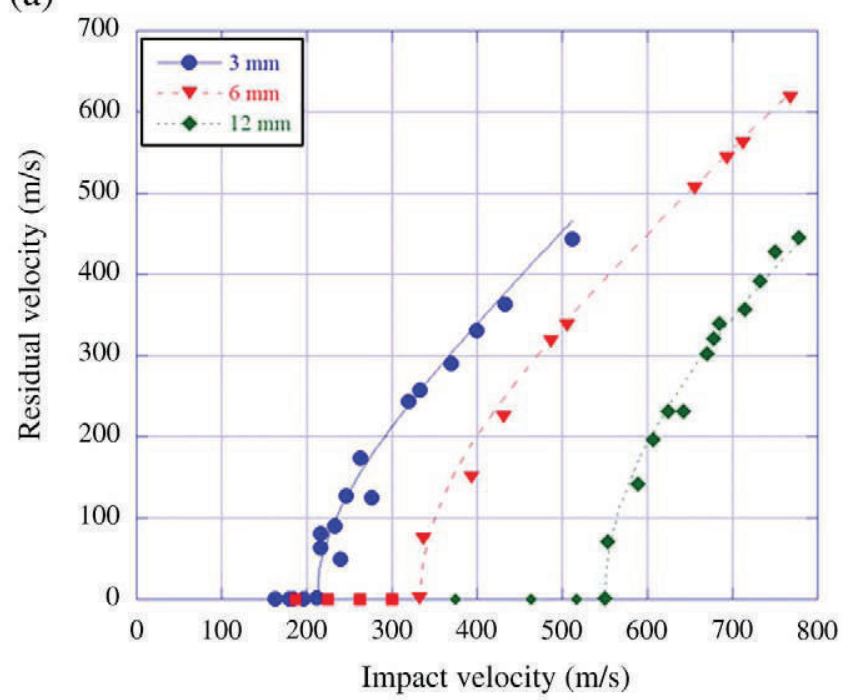

(b)

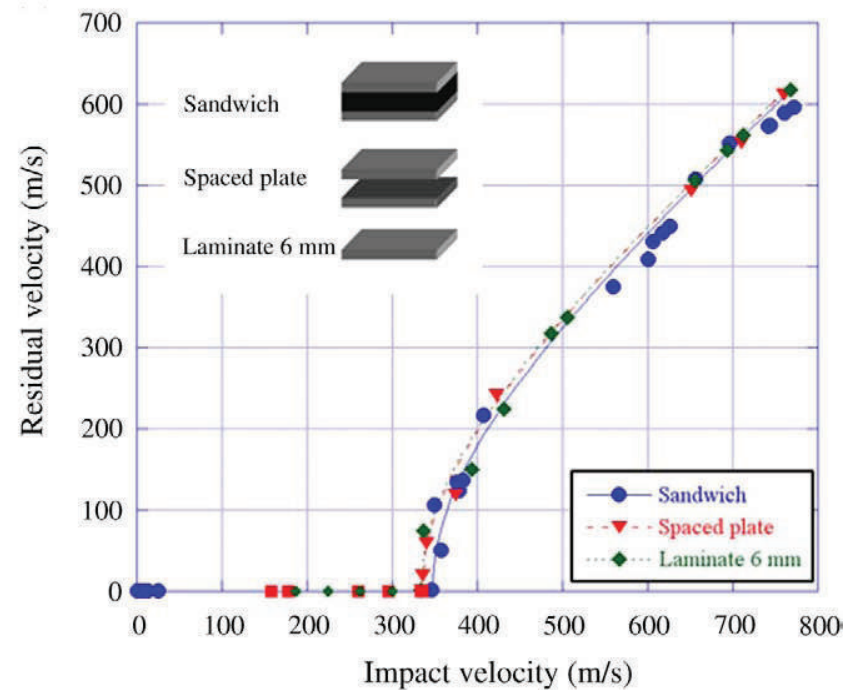

Fig. 1. Residual velocity vs. impact velocity.
Table 1

Ballistic limit.

\begin{tabular}{lllllll}
\hline \multirow{2}{*}{ Structures } & \multicolumn{3}{l}{ Monolithic } & & \multicolumn{2}{l}{ Multiplate laminate } \\
\cline { 2 - 3 } & $3 \mathrm{~mm}$ & $6 \mathrm{~mm}$ & $12 \mathrm{~mm}$ & & Spaced plate & Sandwich \\
\hline Ballistic limit $(\mathrm{m} / \mathrm{s})$ & 212 & 332 & 550 & & 334 & 346 \\
Areal density $\left(\mathrm{kg} / \mathrm{m}^{2}\right)$ & 5.9 & 11.9 & 23.8 & & 11.9 & 14.9 \\
$p$ & 2 & 2 & 2 & & 2 & 2 \\
$A$ & 1 & 0.9 & 0.8 & & 0.9 & 0.9 \\
\hline
\end{tabular}

structures, while between the $6 \mathrm{~mm}$ monolithic laminate and the spaced plates the difference was minimal, because the areal density was similar in the three monolithic laminates, as can be seen in Table 1

On the contrary, in the monolithic laminates the ballistic limit increased with thickness, due to the greater areal density with the thickness; in the $12 \mathrm{~mm}$ laminate, the increase reached 2.6 times over that of the $3 \mathrm{~mm}$ thickness. A linear variation of ballistic limit with areal density has been found; a good correlation of data to a straight line is observed. This relationship can be useful in the estimation of the ballistic limit of a laminate. Only two sets of experimental tests of a structure of the same material with two areal densities are required to calculate the ballistic limit for any areal density in the range considered.

In all of the structures the maximum damage areas were reached in the areas surrounding the ballistic limit [7]. For velocities below the ballistic limit the damage area increased with velocity, while for velocities greater than the ballistic limit this decreases with the increase in velocity.

For monolithic laminates (Fig. 2), it was determined that the damage area increases with plate thickness. The $12 \mathrm{~mm}$ laminate showed a damaged area 2.4 times greater than that of the $3 \mathrm{~mm}$ laminate, giving a percentage similar to that of the difference in the ballistic limit.

Fig. 3 shows the damage area according to the impact velocity for the multiplate laminate structures and the $6 \mathrm{~mm}$ monolithic laminate. The maximum damage areas in the spaced plates and sandwich structures are different. Near the ballistic limit in the multiplate structures, the presence of the core enlarged the damage area of the back face sheet of the sandwich structures $25 \%$ more than in spaced

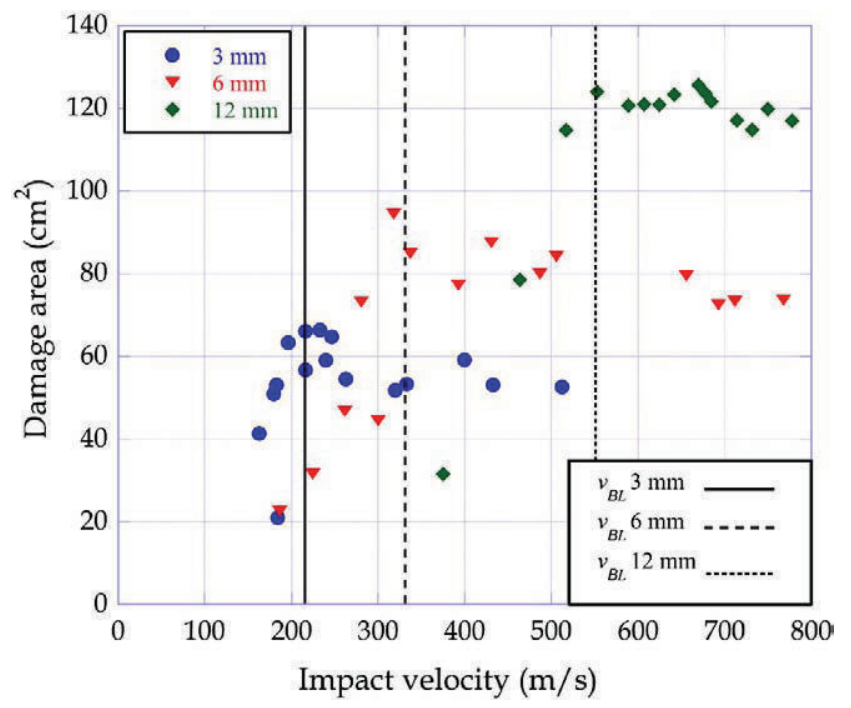

Fig. 2. Damage area in the monolithic laminates. 
(a)

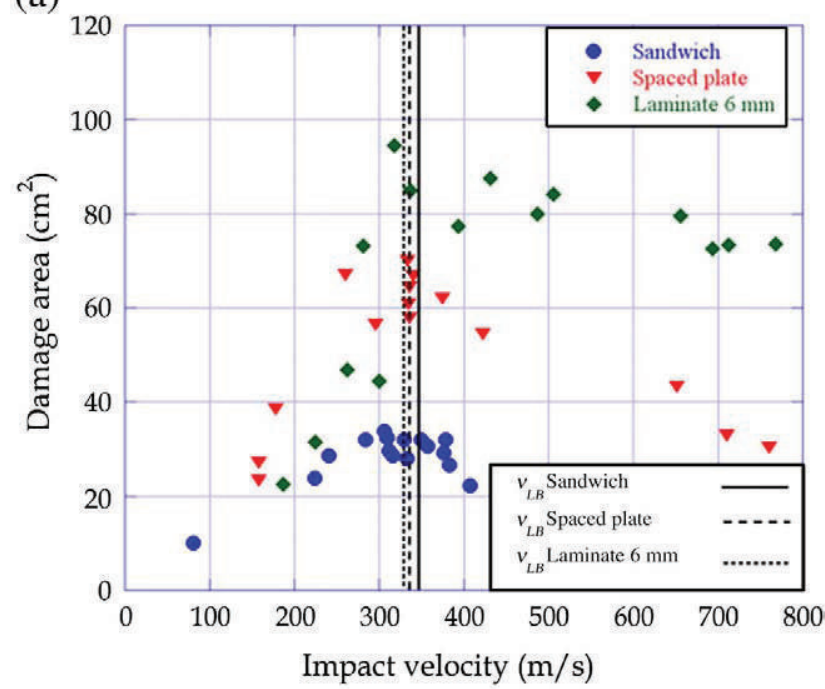

(b)

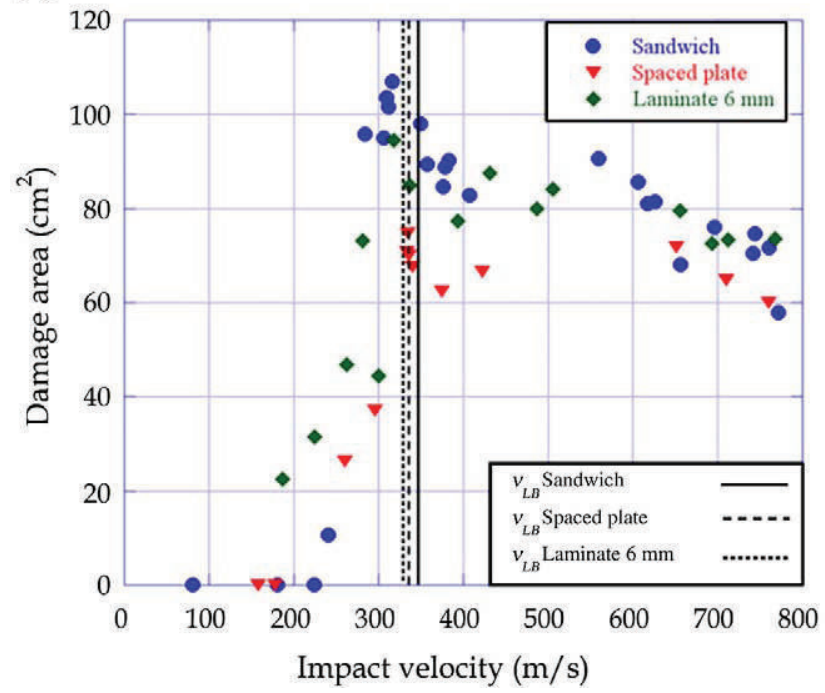

Fig. 3. Damage area in the multiplate laminate structures and monolithic laminate of $6 \mathrm{~mm}$ thick, (a) front face-sheet and (b) back face-sheet.

plates, while in the front face sheet the damage area was twice less. This behaviour could be due to the differences in the propagation of the stress waves produced by the impact between a milieu made of two materials (E glass polyester/foam/E glass polyester) and another made of two separated layers of the same materials (E glass polyester/air/E glass polyester). In the first milieu the stress waves are propagated across the face sheet/core interface, reaching the back face sheet and increasing its damage. In contrast, in the second milieu the propagation of the stress waves across the air between the two face sheets is practically nil, increasing the damage in the front face sheet.

\section{Conclusions}

The ballistic limit and the extension of the damage area increased with the thickness of the monolithic laminates. The ballistic limit in a multiplate laminate structure is similar to that of a monolithic laminate of equal thickness. Nevertheless, the extension of the damage area is different, being greater in the back face sheet of the sandwich than in the spaced plates, whereas the behaviour of the front face sheet is the opposite. These differences are influenced by the propagation of stress waves, which is controlled by the difference in the properties between foam and air.

\section{References}

[1] Ibekwe SI, Mensah PF, Li G, Pang SS, Stubblefield MA. Impact and post impact response of laminated beams at low temperatures. Compos Struct 2007;79:12-7.

[2] Hawyes VJ, Curtis PT, Soutis C. Effect of impact on the compressive response of composite laminates. Compos Part A-Appl S 2001;32:1263-70.

[3] MIL-STD-662F Standard. V50 Ballistic test for armor. Department of Defense Test Method Standard.

[4] De Luca E, Prifti J, Bentheney W, Chous SC. Ballistic impact damage of S2 glassreinforced plastic structural armor. Compos Sci Technol 1997;58:1453-61.

[5] Nunes LM, Paciornik S, D'Almeida JRM. Evaluation of the damage area of glassfiber-reinforced epoxi-matrix composite materials submitted to ballistic impacts. Compos Sci Technol 2004;64:945-54.

[6] Kasano H. Recent advances in high-velocity impact perforation of fiber composite laminates. JSME Int Journal 1999;42(2):147-57.

[7] García-Castillo SK, Sanchéz-Sáez S, Barbero E, Navarro C. Response of pre-loaded laminate composite plates subject to high velocity impact. J Phys IV 2006;134: 1257-63. 